\title{
Prevalence of Depression, Anxiety among International Students in the Health Professions at Southern Medical University, P. R. China
}

\author{
Catherine Mahihu \\ School of Public Health, Southern Medical University, Guangzhou, China \\ Email: cathynjeri10@gmail.com
}

How to cite this paper: Mahihu, C. (2020). Prevalence of Depression, Anxiety among International Students in the Health Professions at Southern Medical University, P. R. China. Open Journal of Social Sciences, $8,161-182$.

https://doi.org/10.4236/jss.2020.812014

Received: September 16, 2020

Accepted: December 13, 2020

Published: December 16, 2020

Copyright $\odot 2020$ by author(s) and Scientific Research Publishing Inc. This work is licensed under the Creative Commons Attribution International License (CC BY 4.0).

http://creativecommons.org/licenses/by/4.0/

(c) (i) Open Access

\begin{abstract}
Introduction: International students experience acculturative stress during the adaptation period into a new country, leading to the development of mental health issues such as depression and anxiety. This issue may be particularly important for international students in the health professions who are exposed to more stressors than usual. This study aims to determine the prevalence of depression, anxiety, and associated factors among international students in the health professions. Methods: This study employed a descriptive cross-sectional research design. A sample of 114 international students from Southern Medical University (SMU) was screened for depression and anxiety using the Hospital Anxiety and Depressive Scale (HADS) during the 2019-2020 academic year. Descriptive statistics, including percentages and frequencies, were performed to determine the prevalence of depression and anxiety. Multiple linear regression analysis was utilized to examine associations between depression and anxiety and socio-demographic characteristics. Results: Overall, the prevalence of depression and anxiety was found to be $36 \%$ and $52.63 \%$, respectively. Undergraduate students studying medicine and postgraduates pursuing master's degrees in Plastic Surgery and Laboratory Science had the highest levels of anxiety $(60 \%)$, while Ph.D. students had the highest level of depression (50\%). The period of study in China ( $p=$ $0.037)$, the discipline of study ( $p=0.004)$, and the level of preparedness for coming to China $(p=0.037)$ were significant predictors of depression, while the discipline of study $(p=0.004)$ and socialization $(p=0.040)$ were significant predictors of anxiety. Conclusion: The prevalence of depression and anxiety among the study population was relatively high. The length of time in China and the level of preparedness before coming to China were significant
\end{abstract}


predictors of depression, while socialization was a significant predictor of anxiety. The discipline of study was a predictor of both depression and anxiety. Provision of key information before students arrive in the host country, access to multilingual interactions with school counselors and current students, and social and academic contacts with domestic students are recommended to mitigate the adverse effects of stress faced by international students in the health professions.

\section{Keywords}

Depression, Anxiety, Prevalence, International Students, Health Science Students

\section{Introduction}

Depression and anxiety are common mental illnesses among students in the health professions. Recognition of the factors that cause stress among this population has gained more traction in recent years. Two recently published meta-analyses reported that the global prevalence of depression and anxiety among medical students was 27.0\% (Tam, Lo, \& Pacheco, 2019) and 33.8\% (Quek et al., 2019). According to a systematic review by Ngasa et al. (2020), the prevalence of depressive symptoms among medical students in Africa is between 23.3\% and 76.5\%. Among medical students in China, the mean prevalence of depression and anxiety was $32.74 \%$ and $27.22 \%$ receptively (Mao et al., 2019). Studies from various parts of the world conclude that the prevalence of depressive symptoms is higher among students in the health professions than in individuals in the same age group in the general population (AlFaris, Irfan, Qureshi, Naeem, Alshomrani, Pon-namperuma et al., 2016; Felicilda-Reynaldo et al., 2019; Gomathi, Ahmed, \& Sreedharan, 2012; Kebede, Anbessie, \& Ayano, 2019; Rotenstein, Ramos, Torre, Segal, Peluso, Guille et al., 2016). However, the majority of these studies focused on domestic medical students and generally overlooked international students in the health professions.

While crucial mental health and well-being concerns for international students have been identified, factors influencing the mental health of international students enrolled in health degree courses have yet to be fully determined. Unlike domestic students, international students are likely to have unique characteristics in that they are away from home, and may face several negative experiences during the adjustment process into a new country and culture. International students may develop feelings of hopelessness, depression, and anxiety due to acculturative stress (Deb, McGirr, \& Sun, 2016; Philip, Colburn, Underwood, \& Bayne, 2019; Sümer, Poyrazli, \& Grahame, 2008; Wen \& Hu, 2018).

Furthermore, the environment of health professional education institutions provides unique and significant stressors for students in the health professions. This may be particularly important for international students in the health pro- 
fessions who are exposed to more stressors than usual that could cause them to develop depression and anxiety. If left unchecked, the consequences of depression and anxiety will not only have a noticeable negative effect on students' function in school but also later on in their careers as they deliver services to individuals, families, and communities (Deb et al., 2016; Pan, Wen, Zhao, Hu, Li, Zhang et al., 2016). Considering the challenges faced by international students in the health profession, their mental health condition needs further investigation (Moutinho et al., 2017). Moreover, China has a growing population of international students, but only a few studies on depression and anxiety among this population are covered in the English language literature (Liu et al., 2016). Therefore, it is essential to bring more attention to this topic to understand the extent and severity of the problem. This study aims to determine the prevalence of depression, anxiety, and the associated socio-demographic factors among international students in the health professions studying at Southern Medical University (SMU) in Guangzhou, China.

\subsection{Review of Literature}

\subsubsection{International Students in China}

Individuals travel overseas for multiple reasons, including holidays, study, and business interests. However, in the past two decades, there has been a significant rise in the number of international students pursuing higher education in various developed countries (McKenna, Robinson, Penman, \& Hills, 2017). In the past twenty years, the number of international students flocking into China has grown exponentially (Yu et al., 2014). There are approximately 328,000 students from more than 200 countries and regions across the globe in China (Yu et al., 2014). With the rise in the number of international students in China, there is a need to examine and evaluate the mental health issues developed by these students as they adapt to China's culture, norms, and expectations (Yu et al., 2014).

\subsubsection{Depression and Anxiety among International Students}

Studies show that due to adjustment problems, international students face a higher risk of developing mental health problems such as depression and anxiety (Dao, Lee, \& Chang, 2007; Liu et al., 2016; Sümer et al., 2008; Hu \& Zhang, 2013). A study among international students in a United States university revealed that $45 \%$ of the students had depressive symptoms, while $24 \%$ were suffering from anxiety (Shadowen, Williamson, Guerra, Ammigan, \& Drexler, 2019). Another study carried out on a sample of international students in northern Japan indicated that $41 \%$ of the participants had depressive symptoms (Eskanadrieh et al., 2012). Several authors have demonstrated that unlike domestic students, international students are faced with several challenges that hinder their adjustment and affect their mental health (Ogunsanya, Bamgbade, Thach, Sudhapalli, \& Rascati, 2018; Skromanis et al., 2018; Yeh \& Inose, 2003). A study carried out in Japan indicated that the prevalence of depressive symptoms among international students was $37.1 \%$, which was higher than that of domes- 
tic students at 29\% (Nguyen, Le, \& Meirmanov, 2019). Influential factors such as language competency, lack of preparedness, lower income, lower educational attainment, and high anxiety affect their mental health and well-being (Ogunsanya et al., 2018).

\subsubsection{Mental Health Challenges among International Students in the Health Professions}

Health professional education institutions around the globe have long been considered stressful environments for students entering tertiary education due to the long hours of study, and the stress associated with the high workload (Haldorsen, Bak, Dissing, \& Petersson, 2014). For international students pursuing health professional courses, their stress is further compounded by learning difficulties, acculturative stress, cultural stress, financial burdens, and the fact that they are required to engage in complex communication in foreign languages (Malau-Aduli, 2011; McKenna et al., 2017; Yeh \& Inose, 2003). This complex situation is true for both undergraduate and postgraduate international students. However, for international graduate students, the combination of a rigorous postgraduate education with the challenges of dealing with a different environment and culture could add even more stress that could lead to mental health issues (Ogunsanya et al., 2018).

Language barriers, poor social adjustment, and stigma on mental health prevent most international students, especially from Asian and African countries from seeking much needed psychological assistance (Hyun, Quinn, Madon, \& Lustig, 2007; Iskra, 2017; Poyrazli et al., 2004). The level of social adjustment depends on the international student's ability to interact with members of the host country (Poyrazli, Kavanaugh, Baker, \& Al-Timimi, 2004). Reduced levels of social interaction with the members of the host country can lead to cultural stress (Iskra, 2017; Poyrazli et al., 2004). Depression and anxiety amongst students in the health profession students not only affects students' lives but may perhaps also have ramifications on patient care in the end (Puthran, Zhang, Tam, \& Ho, 2016).

\subsubsection{Variables Related to Depression and Anxiety}

Studies show that socio-demographic factors influence the manifestation of mental health issues in university students; however, there are inconsistent associations between factors such as age, marital status and religion, and the indication of mental health issues such as depression and anxiety (Gulec Oyekcin, Sahin, \& Aldemir, 2017). Furthermore, inconsistencies are present in studies assessing factors such as gender and ethnicity that contribute to depression and anxiety in university students (Gulec Oyekcin et al., 2017; Jasso-Medrano \& López-Rosales, 2018; Sarokhani et al., 2013; Shamsuddin, Fadzil, Ismail, Shah, Omar, Muhammad et al., 2013). A study in Malaysia showed a noteworthy correlation between gender, age, and mental health issues in university students (Shamsuddin, Fadzil, Ismail, Shah, Omar, Muhammad et al., 2013). A study in Kenya indicated a significant link between religion, age, and depressive symptoms among univer- 
sity students (Othieno, Okoth, Peltzer, Pengpid, \& Malla, 2014).

Studies among international students also show inconsistent relationships between socio-demographic factors and levels of depression and anxiety. A study in the United States on international students showed a significant correlation between age, English proficiency to both depression and anxiety, but no association was found between gender and student's depression and anxiety levels (Sümer et al., 2008). Another study in northern Japan indicated a correlation between gender and depression (Eskanadrieh et al., 2012), while another study in southern Japan found no association between age, gender, and depression among international students, but noted a positive relationship between the length of stay and depression (Nguyen et al., 2019). Reports also indicated that international students face financial constraints that have a significant impact on their mental health (Akhtar, Herwig, \& Faize, 2019; AlFaris, Irfan, Qureshi, Naeem, Alshomrani, Pon-namperuma et al., 2016; Han, Han, Luo, Jacobs, \& Jean-Baptiste, 2013).

Studies show that poor English language proficiency while studying in English speaking developed countries affects academic performance, leading to stress and mental health issues for international students in the health professions (Mori, 2000; Yeh \& Inose, 2003). There is little research to ascertain whether this is true for international students studying in China. Universities in China offer courses in both English and Chinese. A majority of international students in the health professions in China's higher education intuitions are enrolled in English-taught courses. However, these students still face language barriers and difficulties navigating with little to no Chinese proficiency on University campuses.

It is important to ascertain whether these factors pertain to international students in the health professions studying at SMU. Therefore, the study aims to examine the variables covered in literature such as age, gender, socio-economic status, the discipline of study, length of stay in the country, including preparedness, socialization, and Chinese language proficiency and their relation to the manifestation of depressive symptoms and anxiety among international students in the health professions in this setting.

\subsection{Research Questions}

1) What is the prevalence of depressive and anxiety symptoms among international students in the health professions at SMU?

2) Is there a relationship between socio-demographic characteristics and mental health among the study population?

3) What are the socio-demographic predictors of depression and anxiety among the study population?

\section{Methodology}

\subsection{Setting and Population}

This study was carried out on both graduate, and undergraduate international 
students without Chinese citizenship enrolled at SMU, pursuing medicine and healthcare science degrees. SMU is one of China's premier institutes of higher learning situated in Guangzhou, the capital city of Guangdong Province, with a population of 1,043 international students from over 60 countries. SMU offers English-taught medical programs including bachelor's, master's, and doctoral degree courses. The majority of the international students at SMU are undergraduate students pursuing a medical degree, which takes five years plus a one-year internship. The university has a growing population of international master's and doctoral degree students pursuing two to three-year programs in a variety of specialization areas including clinical medicine, public health, nursing, and surgery, among other medicine and healthcare science-related courses.

The study targeted undergraduate international students attending the schools of Medicine and Clinical Medicine, and graduate students attending the schools of Medicine, Clinical Medicine, Health Management, and Public Health of all academic years during the fall semester of the 2019-2020 academic year. The undergraduate participants were majoring in Bachelor of Medicine and Bachelor of Surgery (MBBS). The master's and doctorate students were majoring in public health, plastic surgery, surgery, nursing, laboratory sciences, and cardiovascular diseases.

\subsection{Study Design and Sampling}

This study employed a descriptive cross-sectional research design. Participants of the study were requested to complete an online-based questionnaire containing items about their socio-demographic characteristics and mental health status at the end of the fall semester in the 2019-2020 academic year (January 2020). A Sample of 114 international students from SMU participated in this study by completing an online survey.

Students who agreed to participate in the study were screened according to the following inclusion and exclusion criteria.

\section{Inclusion criteria}

- Students of foreign nationality.

- Came to China to obtain a formal education.

- All international graduate and undergraduate students pursuing medicine and healthcare science degrees, where English is the primary medium of instruction.

\section{Exclusion criteria}

- Refusal to participate in the study.

- Students with Chinese Citizenship.

\subsection{Description of the Procedure}

The study obtained approval from the Ethics Committee involved in research at SMU before subject recruitment and data collection. The questionnaire was distributed online through class monitors on the students' specific WeChat class 
groups. A detailed introduction of the research was given on the online platform for this study. Participation was voluntary and the anonymity of participants was assured.

\subsection{Data Collection Instrument}

\subsubsection{Socio-Demographic Data}

The questionnaire used in the study comprised of self-designed questions on the socio-demographic characteristics of the study population. Data collected included age, gender, marital status, religion, country of origin, educational level (undergraduate or graduate), the discipline of study, social-economic status, length of stay in China, and proficiency in the Chinese language. An item measuring the student's social contact patterns was included to assess which groups of people they socialized with the most-Chinese or non-Chinese students.

\subsubsection{Hospital Anxiety and Depressive Scale (HADS)}

Depressive and anxiety symptoms were measured using the Hospital Anxiety and Depressive Scale (HADS). HADS is a commonly used scale to assess depression and anxiety levels in an individual (Djukanovic, Carlsson, \& Årestedt, 2017). The questionnaire contains 14 questions, with seven items related to depression and another seven related to anxiety. Each item has a score ranging from 0 - 3. Thus, depending on the level of depression and anxiety, the scores can vary from $0-21$ (Bocerean \& Dupret, 2014). The cut-off score for each subscale is a score greater or equal to 8 (Kebede et al., 2019; Tesfaw et al., 2016). HADS has been widely used and validated for use among the general population including the medical student population in various countries (El-Gilany, Amr, \& Hammad, 2008; Francis, Gill, Yit Han, Petrus, Azhar, Ahmad Sabki et al., 2019; Kebede et al., 2019; Waqas et al., 2015).

\subsubsection{Data analysis and Management Procedures}

Statistical Package for Social Sciences (SPSS) version 25 was used to tabulate and analyze data obtained. Descriptive statistics including percentages, frequencies, means, and standard deviations were utilized to analyze the variables concerning the study participants. The study used multiple linear regression analysis to examine associations between depression and anxiety and socio-demographic characteristics.

\section{Result}

\subsection{Socio-Demographic Characteristics of the Students}

Out of the 114 students that participated, $49.12 \%$ identified as female and 50.88\% identified as male (see Table 1). A majority (70.18\%) of the participants were undergraduate students and the rest were students pursuing their master's and Doctor of Philosophy (Ph.D.) degrees. All the undergraduate participants were majoring in MBBS (70.18\%). At the graduate level, the majority $(21.93 \%)$ of the students were pursuing master's degrees in public health, $4.38 \%$ were pursuing 
Table 1. Socio-demographic characteristics of international students.

\begin{tabular}{|c|c|c|}
\hline Characteristics & Frequency & $\%$ \\
\hline \multicolumn{3}{|l|}{ Age groups } \\
\hline 18 - 24 years old & 82 & 71.93 \\
\hline 25 - 34 years old & 21 & 18.42 \\
\hline 35 - 44 years old & 11 & 9.65 \\
\hline Mean Age & & $20.15 \pm 1.9$ \\
\hline \multicolumn{3}{|l|}{ Gender } \\
\hline Female & 56 & 49.12 \\
\hline Male & 58 & 50.88 \\
\hline \multicolumn{3}{|l|}{ Marital status } \\
\hline Single & 95 & 83.33 \\
\hline Married, Divorced, Separated & 19 & 16.67 \\
\hline \multicolumn{3}{|l|}{ Place of Origin } \\
\hline Asian Countries & 66 & 58.30 \\
\hline African Countries & 42 & 37.40 \\
\hline Countries in Europe, America, and Oceania & 5 & 4.50 \\
\hline \multicolumn{3}{|l|}{ Years in China } \\
\hline$<6$ months -1 year & 36 & 31.58 \\
\hline $1-2$ years & 51 & 44.74 \\
\hline $2-4$ years & 22 & 19.30 \\
\hline $4-5$ years & 5 & 4.39 \\
\hline \multicolumn{3}{|l|}{ Religion } \\
\hline Christian & 31 & 27.19 \\
\hline Islam & 44 & 38.60 \\
\hline Hinduism & 30 & 26.32 \\
\hline Buddhism & 4 & 3.51 \\
\hline None & 4 & 3.51 \\
\hline Other & 1 & 0.88 \\
\hline \multicolumn{3}{|l|}{ Discipline of Study } \\
\hline Bachelor of Medicine and Bachelor of Surgery (MBBS) & 80 & 70.18 \\
\hline Masters of Public Health (MPH) & 25 & 21.93 \\
\hline Master's Degree (Plastic Surgery, Laboratory Science) & 5 & 4.38 \\
\hline $\begin{array}{c}\text { Doctorate (Ph.D.) (Public Health, Surgery, Nursing, and } \\
\text { Cardiovascular diseases) }\end{array}$ & 4 & 3.51 \\
\hline \multicolumn{3}{|l|}{ Highest educational achievement } \\
\hline Undergraduate & 107 & 93.86 \\
\hline Graduate & 7 & 6.15 \\
\hline Socio-economic level & & \\
\hline
\end{tabular}




\section{Continued}

\begin{tabular}{ccc}
\hline Low-income & 15 & 13.16 \\
Middle-income & 76 & 66.67 \\
High-income & 23 & 20.17 \\
Level of preparedness before coming to China & & \\
Not well prepared & 78 & 68.42 \\
Well prepared & 36 & 31.58 \\
Pattern of socialization & & \\
Chinese students & 14 & 12.28 \\
Non-Chinese students & 100 & 87.72 \\
Chinese language proficiency & & \\
Not/somewhat proficient & 83 & 72.81 \\
Proficient & 31 & 27.19 \\
\hline
\end{tabular}

a. Sample of a Table footnote ( Table footnote is dispensable).

master's degrees in laboratory sciences and plastic surgery, and $3.51 \%$ were Ph.D. students majoring in public health, surgery, nursing, and cardiovascular diseases. The majority of the students were unmarried (83.33\%). Over a third (38.60\%) of the students were Muslims, 27.19\% were Christians, and 26.32\% were Hindu. Over half (58.30\%) were from Asian countries, $37.40 \%$ were from African countries and the rest (4.5\%) were from countries in Europe, America, and Oceania. The percent of students from low and middle socio-economic backgrounds represented majority (79.83\%) of the students. Almost half (44.74\%) of the students were enrolled for one to two years. Approximately a third (31.58\%) were enrolled for less than six months to a year, $19.30 \%$ had been studying at the school for 2 to 4 years, while the rest (4.39\%) were enrolled for 4 to 5 years. The findings captured by the study indicated that most students (72.81\%) rated themselves as not proficient in the Chinese language. In comparison, less than a third (27.19\%) rated themselves as proficient in the Chinese language. In terms of socialization, the majority of the students (87.72\%) socialized with non-Chinese students, while only $12.28 \%$ socialized with Chinese students.

\subsection{Prevalence of Depression and Anxiety}

Overall, the prevalence of depression and anxiety was found to be $36 \%(n=41)$ and $52.63 \%(n=60)$, respectively (see Figure 1$)$. Findings show that the mean score for anxiety was 7.69 with a standard deviation of 4.25 , while the mean score for depression was 6.49 with a standard deviation of 3.98. Two-thirds (64\%) of the students fell within the normal range $(0-7)$ for depression, however less than half $(48.2 \%)$ scored within the normal range for anxiety. Those that fell within the mild range ( 8 - 11) were $22 \%$ and $24.6 \%$, those within the moderate range (11 - 14) were $9.6 \%$ and $21.1 \%$, and those within the severe range (15 - 21) were $4.4 \%$ and $6.1 \%$ for depression and anxiety respectively. 


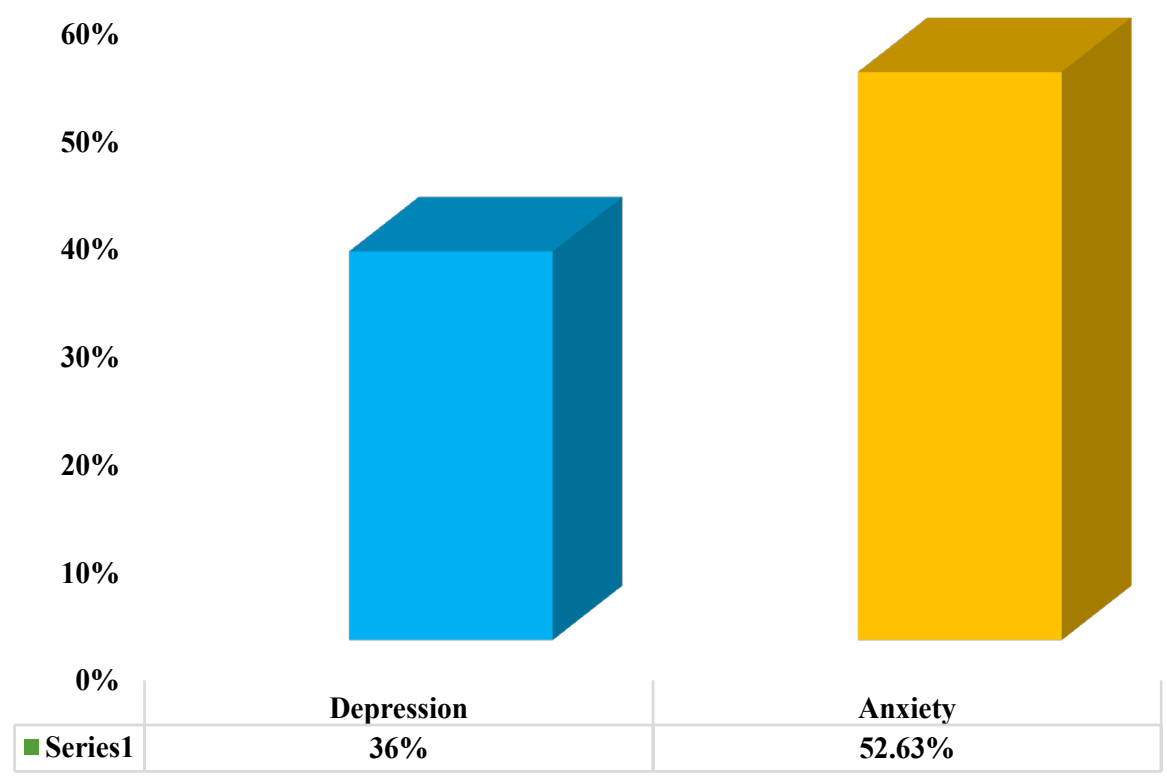

Figure 1. Prevalence of depression and anxiety, among students.

The study revealed that the prevalence of depression was highest among older students above 35 years of age $(\mathrm{n}=11,46 \%)$, while anxiety was highest among students between 18 to 24 years old ( $\mathrm{n}=48,59 \%)$ (see Table 2). Female students showed higher levels of anxiety $(\mathrm{n}=32,57 \%)$ compared to male students $(\mathrm{n}=$ $28,48 \%$ ), while depression levels were the same for both genders (36\%). Students from Europe, the United States, and Oceania countries were found to have higher scores for anxiety $(n=3,60 \%)$. Whereas African students had higher scores for depression ( $\mathrm{n}=18,42 \%)$, but the lowest scores for anxiety $(\mathrm{n}=19,45 \%)$.

Prevalence of depression and anxiety was highest for students who had been in China for one to two years ( $\mathrm{n}=21,41 \%$, and $\mathrm{n}=28,55 \%$ respectively) and lowest among students who had been in China for more than two years $(n=8$, $31 \%$, and $\mathrm{n}=8,31 \%$ respectively). Both first-year and second-year students, had a higher prevalence of anxiety $(n=15,42 \%$ and $n=28,55 \%)$ compared to third, fourth and fifth-year students $(\mathrm{n}=8,31 \%)$.

Students enrolled in MBBS and those pursuing master's degrees in Plastic Surgery and Laboratory Science had the highest level of anxiety $(n=48,60 \%$ and $\mathrm{n}=3,60 \%$ respectively), while Ph.D. students scored higher for depression ( $\mathrm{n}=$ 2, 50\%). Students from low socio-economic backgrounds had a significantly higher prevalence of depression compared to other socio-economic backgrounds $(\mathrm{n}=10,67 \%)$, however, those from middle-income socio-economic backgrounds scored higher for anxiety $(\mathrm{n}=42,55 \%)$. Prevalence of depression and anxiety was highest among students who did not prepare well before coming to China ( $\mathrm{n}=31,40 \%$, and $\mathrm{n}=47,60 \%$ respectively). Higher scores for anxiety were also reported from students who socialize with non-Chinese students ( $\mathrm{n}=$ $55,55 \%)$. Students who were not proficient in the Chinese language scored higher for depression $(n=39,47 \%)$. 
Table 2. Cases of depression and anxiety according to socio-demographic characteristics.

\begin{tabular}{cccccccccc}
\hline \multirow{2}{*}{ Characteristics } & \multicolumn{3}{c}{ Depression } & \multicolumn{5}{c}{ Anxiety } & N \\
\cline { 2 - 7 } & Yes & No & $\%$ & Yes & No & $\%$ & \\
Age groups & & & & & & & & \\
$18-24$ years old & 7 & 53 & 35 & 48 & 34 & 59 & 82 \\
$25-34$ years old & 5 & 14 & 33 & 8 & 13 & 38 & 21 \\
$35-44$ years old & 5 & 46 & 4 & 7 & 36 & 11 \\
Gender & & & & & & & \\
Female & 20 & 36 & 36 & 32 & 24 & 57 & 56 \\
Male & 21 & 37 & 36 & 28 & 30 & 48 & 58
\end{tabular}

\section{Marital status}

Single

Married, Separated, Divorced

\section{Place of origin}

African Countries

Asian Countries

Countries in Europe, America, and Oceania

\section{Years in China}

$$
\begin{gathered}
<6 \text { months }-1 \text { year }(\text { Year } 1) \\
1-2 \text { years }(\text { Year } 2) \\
2-5 \text { years (Year } 3,4 \text {, and } 5 \text { ) }
\end{gathered}
$$

\section{Religion}

Christian

Islam

Buddhism

None

Other

\section{Discipline of Study}

MBBS

Master's Degree (Plastic Surgery,

$$
\text { Laboratory Science) }
$$

Doctorate (Ph.D.) (Public Health, Surgery,

Nursing, and Cardiovascular diseases)

Highest educational achievement

$\begin{array}{lllllll}33 & 62 & 35 & 52 & 43 & 55 & 95 \\ 8 & 11 & 42 & 8 & 11 & 42 & 19\end{array}$

$\begin{array}{lllllll}18 & 24 & 42 & 19 & 23 & 45 & 42 \\ 22 & 44 & 33 & 38 & 28 & 58 & 66 \\ 1 & 4 & 20 & 3 & 2 & 60 & 5\end{array}$


Socio-economic level

$\begin{array}{lccccccc}\text { Low-income } & 10 & 5 & 67 & 7 & 8 & 47 & 15 \\ \text { Middle-income } & 24 & 52 & 32 & 42 & 34 & 55 & 76 \\ \text { High-income } & 7 & 16 & 30 & 11 & 12 & 48 & 23\end{array}$

Level of preparedness before coming to China

$\begin{array}{cccccccc}\text { Not well prepared } & 31 & 47 & 40 & 47 & 31 & 60 & 78 \\ \text { Well prepared } & 10 & 26 & 28 & 13 & 23 & 36 & 36\end{array}$

Pattern of socialization

Chinese students

$\begin{array}{lllllll}6 & 8 & 43 & 5 & 9 & 36 & 14\end{array}$

Non-Chinese students

$\begin{array}{lllllll}35 & 65 & 35 & 55 & 45 & 55 & 100\end{array}$

Chinese language proficiency

Not/somewhat proficient

Proficient

$\begin{array}{lllllll}39 & 44 & 47 & 44 & 39 & 53 & 83 \\ 10 & 21 & 32 & 16 & 15 & 52 & 31\end{array}$

\subsection{Multiple Linear Regression}

Multiple linear regression was calculated to predict depression based on socio-demographic factors including socialization, Chinese proficiency, and period of study in China. The multiple linear regression revealed that the model accounted for $21.4 \%\left(\mathrm{R}^{2}=0.214\right)$ of the variance (see Table 3$)$. The $\mathrm{F}$ value of the model, $(\mathrm{F}(12,100)=2.264)$ was statistically significant at $p$-value $=0.014$. The period of study in China $(p=0.037)$, the discipline of study $(p=0.004)$, and level of preparedness before coming to China $(p=0.037)$ were significant predictors of depression. Length of study was negatively correlated with depression $(\beta=$ $-0.104, p$-value $<0.05)$. Thus, the longer international students lived in China, the less likely they were to suffer from depression. The discipline of study was also found to be a significant predictor of depression $(\beta=-0.284$, $p$-value $<$ 0.05). The findings suggest that students who pursued Ph.D. were more likely to have higher levels of depression.

Likewise, a multiple linear regression was calculated to predict anxiety based on socio-demographic factors, including factors mentioned earlier. A significant regression equation was found $\left(\mathrm{F}(12,100)=1.930, p=0.039\right.$, with an $\mathrm{R}^{2}$ of 0.188 (see Table 4$)$. The multiple linear regression revealed that the discipline ( $p=$ $0.004)$ and socialization $(p=0.040)$ were significant predictors of anxiety. The discipline of study and socialization were negatively correlated with anxiety $(\beta=$ $-0.331, p$-value $<0.05$, and $\beta=-0.255, p$-value $<0.05)$. The findings suggest that students who pursued MBBS and master's degrees in Plastic Surgery and Laboratory Science were more likely to have a higher severity of anxiety. The results also indicate that international students who socialized with Chinese students were less likely to report anxiety symptoms. 
Table 3. Multiple linear regression analysis for variables predicting depression $(\mathrm{N}=114)$.

\begin{tabular}{ccccc}
\hline \multicolumn{5}{c}{ Model Summary } \\
\hline Model & $\mathrm{R}$ & R Square & Adjusted R Square & Std. Error of the Estimate \\
\hline 1 & $0.462^{\mathrm{a}}$ & 0.214 & 0.119 & 0.66081 \\
\hline
\end{tabular}

a. Predictors: (Constant), Socialization, Age, Gender, Preparation for coming to China to study, Religion, Family monthly income, Period of studying in China, Marital status, Discipline of study, Chinese skills, Place of origin, Highest degree before coming to China.

\begin{tabular}{|c|c|c|c|c|c|c|}
\hline \multicolumn{7}{|c|}{ ANOVA } \\
\hline \multicolumn{2}{|c|}{ Model } & \multirow{2}{*}{$\begin{array}{c}\text { Sum of Squares } \\
11.861\end{array}$} & \multirow{2}{*}{$\frac{\mathrm{df}}{12}$} & \multirow{2}{*}{$\begin{array}{c}\text { Mean Square } \\
0.988\end{array}$} & \multirow{2}{*}{$\begin{array}{c}\mathrm{F} \\
2.264\end{array}$} & \multirow{2}{*}{$\frac{\text { Sig. }}{0.014^{\text {b* }}}$} \\
\hline 1 & Regression & & & & & \\
\hline & Residual & 43.667 & 100 & 0.437 & & \\
\hline & Total & 55.528 & 112 & & & \\
\hline
\end{tabular}

b. Dependent Variable: Depression; c. Predictors: (Constant), Socialization, Age, Gender, Preparation for coming to China to study, Religion, Family monthly income, Period of studying in China, Marital status, Discipline of study, Chinese skills, Place of origin, Highest degree before coming to China.

\begin{tabular}{cccccc}
\hline \multicolumn{5}{c}{ Coefficients $^{\mathrm{a}}$} \\
$\begin{array}{c}\text { Explanatory } \\
\text { variables }\end{array}$ & $\begin{array}{c}\text { Unstandardized } \\
\text { Coefficients }\end{array}$ & $\begin{array}{c}\text { Standardized } \\
\text { Coefficients }\end{array}$ & $\mathrm{t}$ & Sig. \\
\cline { 2 - 6 } & B & Std. Error & Beta & & \\
\hline Constant) & 2.662 & 0.651 & & 4.087 & 0.000 \\
Age & -0.117 & 0.168 & -0.107 & -0.698 & 0.487 \\
Gender & -0.050 & 0.129 & -0.036 & -0.386 & 0.700 \\
Place of origin & 0.103 & 0.149 & 0.082 & 0.693 & 0.490 \\
Religion & -0.029 & 0.067 & -0.043 & -0.436 & 0.664 \\
Study period & -0.104 & 0.049 & -0.207 & -2.111 & $0.037^{*}$ \\
Discipline of study & -0.284 & 0.096 & -0.344 & -2.941 & $0.004^{*}$ \\
Marital status & -0.008 & 0.127 & -0.007 & -0.064 & 0.949 \\
Highest degree attained & 0.225 & 0.163 & 0.222 & 1.380 & 0.171 \\
Family monthly income & 0.016 & 0.059 & 0.025 & 0.269 & 0.788 \\
Preparedness & 0.173 & 0.082 & 0.211 & 2.115 & $0.037^{*}$ \\
Chinese skills & 0.088 & 0.084 & 0.124 & 1.043 & 0.299 \\
Socialization & -0.107 & 0.106 & -0.096 & -1.012 & 0.314 \\
\hline
\end{tabular}

a. Dependent Variable: Depression; b. ${ }^{\star} p<0.05$.

Table 4. Multiple linear regression analysis for variables predicting anxiety $(\mathrm{N}=114)$.

\begin{tabular}{ccccc}
\hline \multicolumn{4}{c}{ Model Summary } \\
\hline Model & $\mathrm{R}$ & R Square & Adjusted R Square & Std. Error of the Estimate \\
\hline 1 & $0.434^{\mathrm{a}}$ & 0.188 & 0.091 & 0.76570 \\
\hline
\end{tabular}

a. Predictors: (Constant), Socialization, Age, Gender, Preparation for coming to China to study, Religion, Family monthly income, Period of studying in China, Marital status, Discipline of study, Chinese skills, Place of origin, Highest degree before coming to China. 


\begin{tabular}{ccccccc}
\hline \multicolumn{7}{c}{ ANOVA } \\
\hline \multirow{2}{*}{1} & Model & Sum of Squares & df & Mean Square & F & Sig. \\
\hline & Regression & 13.579 & 12 & 1.132 & 1.930 & $0.039^{\text {b* }}$ \\
& Residual & 58.630 & 100 & 0.586 & & \\
& Total & 72.209 & 112 & & & \\
\hline
\end{tabular}

a. Dependent Variable: Anxiety; b. Predictors: (Constant), Socialization, Age, Gender, Preparation for coming to China to study, Religion, Family monthly income, Period of studying in China, Marital status, Discipline of study, Chinese skills, Place of origin, Highest degree before coming to China.

\begin{tabular}{cccccc}
\hline & \multicolumn{5}{c}{ Coefficients $^{\mathrm{a}}$} \\
$\begin{array}{c}\text { Explanatory } \\
\text { variables }\end{array}$ & $\begin{array}{c}\text { Unstandardized } \\
\text { Coefficients }\end{array}$ & $\begin{array}{c}\text { Standardized } \\
\text { Coefficients }\end{array}$ & $\mathbf{t}$ & Sig. \\
\cline { 2 - 6 } & B & Std. Error & Beta & & \\
\hline Constant) & 2.251 & 0.755 & & 2.983 & 0.004 \\
Age & 0.340 & 0.194 & 0.272 & 1.747 & 0.084 \\
Gender & 0.077 & 0.150 & 0.048 & 0.515 & 0.608 \\
Place of origin & -0.038 & 0.173 & -0.026 & -.0220 & 0.826 \\
Religion & 0.022 & 0.078 & 0.029 & 0.287 & 0.774 \\
Study period & -0.044 & 0.057 & -0.077 & -0.775 & 0.440 \\
Discipline of study & -0.331 & 0.112 & -0.352 & -2.963 & $0.004^{*}$ \\
Marital status & -0.105 & 0.148 & -0.081 & -0.711 & 0.479 \\
Highest degree attained & 0.299 & 0.189 & 0.259 & 1.579 & 0.117 \\
Family monthly income & -0.023 & 0.068 & -0.033 & -0.341 & 0.734 \\
Preparedness & 0.054 & 0.095 & 0.058 & 0.573 & 0.568 \\
Chinese skills & 0.142 & 0.097 & 0.175 & 1.455 & 0.149 \\
Socialization & -0.255 & 0.122 & -0.201 & -2.080 & $0.040^{*}$ \\
\hline
\end{tabular}

a. Dependent Variable: Anxiety; b. ${ }^{\star} p<0.05$.

\section{Discussion}

\subsection{Prevalence of Depression and Anxiety}

This study sought to determine the prevalence of depression and anxiety among international students in the health professions and their socio-demographic predictors. The study results indicate that the proportion of the students who had anxiety was higher than those who had depression. Over half $(52.63 \%)$ of the students were found to have anxiety. The results of this study are in line with study results from Germany among international medical students, where about half (49\%) were found to have moderate to severe levels of anxiety (Akhtar et al., 2019). Similarly, a study in Bahrain found that the magnitude of medical students with anxiety was (51\%) (Mahroon et al., 2018), using Beck's Anxiety Inventory (BAI) scale. The prevalence of anxiety in the current study was lower than studies undertaken among medical students in Egypt (73\%) (Fawzy \& 
Hamed, 2017) using the Depression Anxiety Stress Scale (DASS 21) and higher than the global prevalence of 33.8\% (Quek et al., 2019). Literature shows that the prevalence of anxiety was consistently higher among medical students compared to other students pursuing humanities and the general public, irrespective of the measuring scale utilized (Dyrbye, Thomas, \& Shanafelt, 2006; Sahoo \& Khess, 2010).

The prevalence of depression (36\%) in the current study is similar to outcomes reported in Ethiopia among medical students (30.1\% - 35.54\%) (Kebede et al., 2019) using the HADs scale, in Cameroon (30.6\%) (Ngasa et al., 2017), using the 9-Item-Patient Health Questionnaire (PHQ-9), and in Germany (34.92\%) among medical students (Seweryn et al., 2015), using the Beck Depression Inventory (BDI). Studies in China (19.9\%) (Pan, Wen, Zhao, Hu, Li, Zhang et al., 2016), Portugal (26.03\%) (Seweryn et al., 2015), and in the United Kingdom (2.7\% - 10.5\%) (Quince, Wood, Parker, \& Benson, 2012) reported lower outcomes among medical students. The disparity in the outcomes for depression and anxiety in these studies could be due to the different scales such as BAI, DASS 21, HADs, and PHQ-9 used to measure depressive symptoms.

\subsection{Predictors of Depression and Anxiety}

The current study revealed that the period of study in China was a predictor of depression. The prevalence of depression was highest among students in their first and second year in China. The results of this study are echoed in other literature that indicates that international students were more depressed in their first year compared to the domestic students in the same academic year (Sümer et al., 2008). In contrast, other studies indicate that medical students in their third year had a higher likelihood of reporting symptoms of depression compared to students in the first year (Nguyen et al., 2019). The possible explanation for the higher rate of depression among first and second-year international students is due to the adjustment difficulties they experienced during their first two years in the host country, coupled with demanding coursework and feelings of loneliness while dealing with culture shock. A related factor is the level of preparation done by the students before coming to China. Findings from our study indicate inadequate preparation before coming to China is associated with depression. Students should be encouraged to learn as much about their new host country before leaving their home country. International education institutions can strengthen their provision of information and resources to new students before their arrival (Liu et al., 2016).

The study results indicate that the discipline of study is a predictor of depression and anxiety. Undergraduate students pursuing MBBS and postgraduates pursuing master's degrees in Plastic Surgery and Laboratory Science had a higher prevalence of anxiety, compared to students seeking master's degrees in public health, while depression symptoms were higher among Ph.D. students. This outcome is in line with other research indicating that the discipline of study 
among students in the health profession was one of the main factors associated with symptoms of depression (AlFaris, Irfan, Qureshi, Naeem, Alshomrani, Pon-namperuma et al., 2016). The courses' distinctive rigorous nature contributes to the stressful environment, depressive symptoms, and anxiety the students face throughout their training.

In this study, socialization is a predictor of anxiety. Students who socialized with Chinese students were less likely to have depression and anxiety. However, the majority of the students indicated that they socialize with non-Chinese Students. The main underlying issue that hinders students from socializing with Chinese domestic students could be the language barrier. A study regarding acculturative and depression among international students in China conducted by Liu, Y., et al. (2016) pointed out that international students who spoke English as their second language faced fewer challenges adjusting in English-speaking countries. The study continued to note that the social adjustment of these students might be more challenging in China since most Chinese are less likely to speak English as a second language (Liu et al., 2016). Programs to teach incoming international students the Chinese language go a long way in aiding the adjustment of international students into China. In addition to these programs, encouraging interactions between Chinese and international students could mitigate the social adjustment problems encountered by these students.

Regarding other socio-demographic factors, this study did not support previous studies indicating that age, gender, religion, financial constraints, language, and ethnicity as predictors of depression and anxiety (Eskanadrieh et al., 2012; Ogunsanya et al., 2018; Othieno et al., 2014; Shamsuddin, Fadzil, Ismail, Shah, Omar, Muhammad et al., 2013).

\subsection{Limitations}

There are several limitations to our study. First, the sample used in the study represents the total population of international students enrolled in the university taking courses where English is the primary medium of instruction. However, since the data was collected online, the return rate is only $11 \%$. The main reason is data collection was carried out at the end of the fall semester, in the middle of January 2020, before news of the coronavirus disease 2019 (COVID-19) outbreak in Wuhan, China. To avoid response bias, we decided not to send further reminders of the online survey to the students since news of the outbreak would have affected students' perception of their anxiety and depression. Secondly, the correlational nature of the study examining the socio-demographic predictors of depression and anxiety may not infer causation. The higher prevalence of anxiety and depression among students in the health profession could also emanate from academic workload, lack of sleep, language barriers during interactions with patients during clinical practice, challenges adapting to different healthcare systems, discrimination, exposure to deaths of patients, and receiving saddening news from home (McKenna et al., 2017; Quek et al., 2019). 


\section{Implications and Recommendations}

The results of this study will assist educators and school counselors to identify international students in the health professions at risk of developing depression and anxiety. The long-term effects of depression and anxiety amongst these students have negative implications that extend to the individuals, households, and communities they will serve later in their careers. Therefore, early detection of depression and anxiety symptoms among this population is paramount and has a greater impact on our society as a whole.

The results of this study illustrate how inadequate preparation of international students before coming to China is associated with depression. To increase the level of preparedness of students before coming to China, education institutions can strengthen the provision of information on culture, norms and standards of the host university/institution and country including general information such as weather, school and local community maps with key locations to new students before and after their arrival. The provision of information before and after arrival into the host country reduces stress encountered by international students during the adaptation process into a new culture.

The study also found that the discipline of study is a predictor of depression and anxiety. We suggest education institutions increase awareness of and access to psychological support for students pursuing courses that are rigorous in nature since there are more susceptible to developing depressive symptoms and anxiety during their training.

The results of this study illustrate how inadequate preparation of international students before coming to China is associated with depression. To increase the level of preparedness of students before coming to China, education institutions can strengthen the provision of information on culture, norms and standards of the host university/institution and country including general information such as weather, school and local community maps with key locations to new students before and after their arrival. The provision of information before and after arrival into the host country reduces stress encountered by international students during the adaptation process into a new culture. Furthermore, we suggest institutions provide access to multilingual interactions with school counselors and current students who can assist, guide, and mentor students after they arrive and during their stay in the host country.

Social and academic interactions between Chinese and international students and cross-cultural communication training programs should be encouraged. This would have a favorable impact on the students' adjustment process and thereby alleviating acculturative stress and the development of mental health issues. Further research is needed to evaluate the potential reasons for the high rate of anxiety and depression and their associated factors among international students in the health professions.

\section{Conclusion}

The prevalence of depression (36\%) and anxiety (52.63\%) among the study pop- 
ulation was relatively high. The length of time in China and the level of preparedness before coming to China were significant predictors of depression, while socialization was a significant predictor of anxiety. The discipline of study was a predictor of both depression and anxiety. The findings of this study highlight the growing need to shed more light on the mental health issues facing international students in the health professions.

\section{Conflicts of Interest}

The author declares no conflicts of interest regarding the publication of this paper.

\section{References}

Akhtar, M., Herwig, B. K., \& Faize, F. A. (2019). Depression and Anxiety among International Medical Students in Germany: The Predictive Role of Coping Styles. The Journal of the Pakistan Medical Association, 69, 230-234.

AlFaris, E., Irfan, F., Qureshi, R., Naeem, N., Alshomrani, A., Ponnamperuma, G. et al. (2016). Health Professions' Students Have an Alarming Prevalence of Depressive Symptoms: Exploration of the Associated Factors. BMC Medical Education, 16, 279. https://doi.org/10.1186/s12909-016-0794-y

Bocerean, C., \& Dupret, E. (2014). A Validation Study of the Hospital Anxiety and Depression Scale (HADS) in a Large Sample of French Employees. BMC Psychiatry, 14, 354. https://doi.org/10.1186/s12888-014-0354-0

Dao, T. K., Lee, D., \& Chang, H. L. (2007). Acculturation Level, Perceived English Fluency, Perceived Social Support Level, and Depression among Taiwanese International Students. College Student Journal, 41, 287-295.

https://search.ebscohost.com/login.aspx?drect=true \&db=aph\&AN=25093201\&site=eds -live

Deb, S., McGirr, K., \& Sun, J. (2016). Spirituality in Indian University Students and Its Associations with Socioeconomic Status, Religious Background, Social Support, and Mental Health. Journal of Religion \& Health, 55, 1623-1641. https://doi.org/10.1007/s10943-016-0207-x

Djukanovic, I., Carlsson, J., \& Årestedt, K. (2017). Is the Hospital Anxiety and Depression Scale (HADS) a Valid Measure in a General Population 65-80 Years Old? A Psychometric Evaluation Study. Health and Quality of Life Outcomes, 15, 193-193.

https://doi.org/10.1186/s12955-017-0759-9

Dyrbye, L. N., Thomas, M. R., \& Shanafelt, T. D. (2006). Systematic Review of Depression, Anxiety, and Other Indicators of Psychological Distress among U.S. and Canadian Medical Students. Academic Medicine, 81, 354-373. https://doi.org/10.1097/00001888-200604000-00009

El-Gilany, A. H., Amr, M., \& Hammad, S. (2008). Perceived Stress among Male Medical Students in Egypt and Saudi Arabia: Effect of Sociodemographic Factors. The Annals of Saudi Medicine, 28, 442-448. https://doi.org/10.5144/0256-4947.2008.442

Eskanadrieh, S., Liu, Y., Yamashina, H., Kono, K., Arai, A., Lee, R., \& Tamashiro, H. (2012). Depressive Symptoms among International University Students in Northern Japan: Prevalence and Associated Factors. Kokusai Hoken Iryo (Journal of International Health), 27, 165-170.

Fawzy, M., \& Hamed, S. A. (2017). Prevalence of Psychological Stress, Depression and 
Anxiety among Medical Students in Egypt. Psychiatry Research, 255, 186-194. https://doi.org/10.1016/j.psychres.2017.05.027

Felicilda-Reynaldo, R. F. D., Cruz, J. P., Papathanasiou, I. V., Helen Shaji, J. C., Kamau, S. M., Adams, K. A., \& Valdez, G. F. D. (2019). Quality of Life and the Predictive Roles of Religiosity and Spiritual Coping among Nursing Students: A Multi-Country Study. Journal of Religion and Health, 58, 1573-1591. https://doi.org/10.1007/s10943-019-00771-4

Francis, B., Gill, J. S., Yit Han, N., Petrus, C. F., Azhar, F. L., Ahmad Sabki, Z. et al. (2019). Religious Coping, Religiosity, Depression and Anxiety among Medical Students in a Multi-Religious Setting. International Journal of Environmental Research and Public Health, 16, E259. https://doi.org/10.3390/ijerph16020259

Gomathi, K. G., Ahmed, S., \& Sreedharan, J. (2012). Psychological Health of First-Year Health Professional Students in a Medical University in the United Arab Emirates. Sultan Qaboos University Medical Journal, 12, 206-213. https://doi.org/10.12816/0003114

Gulec Oyekcin, D., Sahin, E. M., \& Aldemir, E. (2017). Mental Health, Suicidality and Hopelessness among University Students in Turkey. Asian Journal of Psychiatry, 29, 185-189. https://doi.org/10.1016/j.ajp.2017.06.007

Haldorsen, H., Bak, N. H., Dissing, A., \& Petersson, B. (2014). Stress and Symptoms of Depression among Medical Students at the University of Copenhagen. Scandinavian Journal of Public Health, 42, 89-95. https://doi.org/10.1177/1403494813503055

Han, X., Han, X., Luo, Q., Jacobs, S., \& Jean-Baptiste, M. (2013). Report of a Mental Health Survey among Chinese International Students at Yale University. Journal of American College Health, 61, 1-8. https://doi.org/10.1080/07448481.2012.738267

Hu, W. H., \& Zhang, Z. (2013). International Students' Adjustment Problems at University: A Critical Literature Review. Academic Research International, 4, 400. http://www.savap.org.pk/journals/ARInt./Vol.4(2)/2013(4.2-41).pdf

Hyun, J., Quinn, B., Madon, T., \& Lustig, S. (2007). Mental Health Need, Awareness, and Use of Counseling Services among International Graduate Students. Journal of American College Health, 56, 109-118. https://doi.org/10.3200/JACH.56.2.109-118

Iskra, S. (2017). The Role of Attachment, Travel Experiences and English Proficiency in International Students' Acculturative Stress and Depressive Symptoms. Journal of International Students, 7, 188-203. https://doi.org/10.32674/jis.v7i2.322

Jasso-Medrano, J. L., \& López-Rosales, F. (2018). Measuring the Relationship between Social Media Use and Addictive Behavior and Depression and Suicide Ideation among University Students. Computers in Human Behavior, 87, 183-191.

https://doi.org/10.1016/j.chb.2018.05.003

Kebede, M. A., Anbessie, B., \& Ayano, G. (2019). Prevalence and Predictors of Depression and Anxiety among Medical Students in Addis Ababa, Ethiopia. International Journal of Mental Health Systems, 13, 30. https://doi.org/10.1186/s13033-019-0287-6

Liu, Y., Chen, X., Li, S., Yu, B., Wang, Y., \& Yan, H. (2016). Path Analysis of Acculturative Stress Components and Their Relationship with Depression among International Students in China. Stress Health, 32, 524-532. https://doi.org/10.1002/smi.2658

Mahroon, Z. A., Borgan, S. M., Kamel, C., Maddison, W., Royston, M., \& Donnellan, C. (2018). Factors Associated with Depression and Anxiety Symptoms among Medical Students in Bahrain. Academic Psychiatry, 42, 31-40. https://doi.org/10.1007/s40596-017-0733-1

Malau-Aduli, B. S. (2011). Exploring the Experiences and Coping Strategies of Interna- 
tional Medical Students. BMC Medical Education, 11, 40.

https://doi.org/10.1186/1472-6920-11-40

Mao, Y., Zhang, N., Liu, J., Zhu, B., He, R., \& Wang, X. (2019). A Systematic Review of Depression and Anxiety in Medical Students in China. BMC Medical Education, 19, 327-327. https://doi.org/10.1186/s12909-019-1744-2

McKenna, L., Robinson, E., Penman, J., \& Hills, D. (2017). Factors Impacting on Psychological Wellbeing of International Students in the Health Professions: A Scoping Review. International Journal of Nursing Studies, 74, 85-94.

https://doi.org/10.1016/j.ijnurstu.2017.06.007

Mori (2000). Addressing the Mental Health Concerns of International Students. Journal of Counseling \& Development, 78, 137-144. https://doi.org/10.1002/j.1556-6676.2000.tb02571.x

Moutinho, I. L., Maddalena, N. C., Roland, R. K., Lucchetti, A. L., Tibirica, S. H., Ezequiel, O. D., \& Lucchetti, G. (2017). Depression, Stress and Anxiety in Medical Students: A Cross-Sectional Comparison between Students from Different Semesters. Revista da Associação Médica Brasileira, 63, 21-28.

https://doi.org/10.1590/1806-9282.63.01.21

Ngasa, S. N., Sama, C. B., Dzekem, B. S., Chang, N., Tindong, M., \& Neba, K. N. (2020). Prevalence and Factors Associated with Depression among Medical Students in Africa; A Systematic Review Study. Research Square. https://doi.org/10.21203/rs.3.rs-15820/v1

Ngasa, S. N., Sama, C.-B., Dzekem, B. S., Nforchu, K. N., Tindong, M., Aroke, D., \& Dimala, C. A. (2017). Prevalence and Factors Associated with Depression among Medical Students in Cameroon: A Cross-Sectional Study. BMC Psychiatry, 17, 216-216. https://doi.org/10.1186/s12888-017-1382-3

Nguyen, H., Le, T., \& Meirmanov, S. (2019). Depression, Acculturative Stress, and Social Connectedness among International University Students in Japan: A Statistical Investigation. Sustainability, 11, 878. https://doi.org/10.3390/su11030878

Ogunsanya, M. E., Bamgbade, B. A., Thach, A. V., Sudhapalli, P., \& Rascati, K. L. (2018). Determinants of Health-Related Quality of Life in International Graduate Students. Currents in Pharmacy Teaching and Learning, 10, 413-422. https://doi.org/10.1016/j.cptl.2017.12.005

Othieno, C. J., Okoth, R. O., Peltzer, K., Pengpid, S., \& Malla, L. O. (2014). Depression among University Students in Kenya: Prevalence and Sociodemographic Correlates. The Journal of Affective Disorders, 165, 120-125. https://doi.org/10.1016/j.jad.2014.04.070

Pan, X. F., Wen, Y., Zhao, Y., Hu, J. M., Li, S. Q., Zhang, S. K. et al. (2016). Prevalence of Depressive Symptoms and Its Correlates among Medical Students in China: A National Survey in 33 Universities. Psychology, Health \& Medicine, 21, 882-889. https://doi.org/10.1080/13548506.2015.1127395

Philip, S., Colburn, A., Underwood, L., \& Bayne, H. (2019). The Impact of Religion/Spirituality on Acculturative Stress among International Students. Journal of College Counseling, 22, 27-40. https://doi.org/10.1002/jocc.12112

Poyrazli, S., Kavanaugh, P. R., Baker, A., \& Al-Timimi, N. (2004). Social Support and Demographic Correlates of Acculturative Stress in International Students. Journal of College Counseling, 7, 73-82. https://doi.org/10.1002/j.2161-1882.2004.tb00261.x

Puthran, R., Zhang, M. W., Tam, W. W., \& Ho, R. C. (2016). Prevalence of Depression amongst Medical Students: A Meta-Analysis. Medical Education, 50, 456-468.

https://doi.org/10.1111/medu.12962

Quek, T. T.-C., Tam, W. W.-S., Tran, B. X., Zhang, M., Zhang, Z., Ho, C. S.-H., \& Ho, R. 
C.-M. (2019). The Global Prevalence of Anxiety among Medical Students: A Meta-Analysis. International Journal of Environmental Research and Public Health, 16, 2735. https://doi.org/10.3390/ijerph16152735

Quince, T. A., Wood, D. F., Parker, R. A., \& Benson, J. (2012). Prevalence and Persistence of Depression among Undergraduate Medical Students: A Longitudinal Study at One UK Medical School. BMJ Open, 2, e001519. https://doi.org/10.1136/bmjopen-2012-001519

Rotenstein, L. S., Ramos, M. A., Torre, M., Segal, J. B., Peluso, M. J., Guille, C. et al. (2016). Prevalence of Depression, Depressive Symptoms, and Suicidal Ideation among Medical Students: A Systematic Review and Meta-Analysis. JAMA, 316, 2214-2236. https://doi.org/10.1001/jama.2016.17324

Sahoo, S., \& Khess, C. R. (2010). Prevalence of Depression, Anxiety, and Stress among Young Male Adults in India: A Dimensional and Categorical Diagnoses-Based Study. The Journal of Nervous and Mental Disease, 198, 901-904. https://doi.org/10.1097/NMD.0b013e3181fe75dc

Sarokhani, D., Delpisheh, A., Veisani, Y., Sarokhani, M. T., Manesh, R. E., \& Sayehmiri, K. (2013). Prevalence of Depression among University Students: A Systematic Review and Meta-Analysis Study. Depression Research and Treatment, 2013, Article ID: 373857. https://doi.org/10.1155/2013/373857

Seweryn, M., Tyrala, K., Kolarczyk-Haczyk, A., Bonk, M., Bulska, W., \& Krysta, K. (2015). Evaluation of the Level of Depression among Medical Students from Poland, Portugal and Germany. Psychiatria Danubina, 27, S216-222.

Shadowen, N. L., Williamson, A. A., Guerra, N. G., Ammigan, R., \& Drexler, M. L. (2019). Prevalence and Correlates of Depressive Symptoms among International Students: Implications for University Support Offices. Journal of International Students, 9, 129. https://doi.org/10.32674/jis.v9i1.277

Shamsuddin, K., Fadzil, F., Ismail, W. S. W., Shah, S. A., Omar, K., Muhammad et al. (2013). Correlates of Depression, Anxiety and Stress among Malaysian University Students. Asian Journal of Psychiatry, 6, 318-323. https://doi.org/10.1016/j.ajp.2013.01.014

Skromanis, S., Cooling, N., Rodgers, B., Purton, T., Fan, F., Bridgman, H. et al. (2018). Health and Well-Being of International University Students, and Comparison with Domestic Students, in Tasmania, Australia. International Journal of Environmental Research and Public Health, 15, 1147. https://doi.org/10.3390/ijerph15061147

Sümer, S., Poyrazli, S., \& Grahame, K. (2008). Predictors of Depression and Anxiety among International Students. Journal of Counseling \& Development, 86, 429-437. https://doi.org/10.1002/j.1556-6678.2008.tb00531.x

Tam, W., Lo, K., \& Pacheco, J. (2019). Prevalence of Depressive Symptoms among Medical Students: Overview of Systematic Reviews. Medical Education, 53, 345-354. https://doi.org/10.1111/medu.13770

Tesfaw, G., Ayano, G., Awoke, T., Assefa, D., Birhanu, Z., Miheretie, G., \& Abebe, G. (2016). Prevalence and Correlates of Depression and Anxiety among Patients with HIV On-Follow Up at Alert Hospital, Addis Ababa, Ethiopia. BMC Psychiatry, 16, 368. https://doi.org/10.1186/s12888-016-1037-9

Waqas, A., Rehman, A., Malik, A., Muhammad, U., Khan, S., \& Mahmood, N. (2015). Association of Ego Defense Mechanisms with Academic Performance, Anxiety and Depression in Medical Students: A Mixed Methods Study. Cureus, 7, e337-e337. https://doi.org/10.7759/cureus.337

Wen, W., \& Hu, D. (2018). The Emergence of a Regional Education Hub: Rationales of 
International Students' Choice of China as the Study Destination. Journal of Studies in International Education, 23, 303-325. https://doi.org/10.1177/1028315318797154

Yeh, C. J., \& Inose, M. (2003). International Students' Reported English Fluency, Social Support Satisfaction, and Social Connectedness as Predictors of Acculturative Stress. Counselling Psychology Quarterly, 16, 15-28.

https://doi.org/10.1080/0951507031000114058

Yu, B., Chen, X., Li, S., Liu, Y., Jacques-Tiura, A. J., \& Yan, H. (2014). Acculturative Stress and Influential Factors among International Students in China: A Structural Dynamic Perspective. PLoS ONE, 9, e96322. https://doi.org/10.1371/journal.pone.0096322 